\title{
Investigating the Status of Supplementary Tuition in the Teaching and Learning of Mathematics
}

\author{
David Mogari \\ Institute for Science and Technology Education, University of South Africa \\ mogarld@unisa.ac.za \\ Hanlie Coetzee \\ Dept. of Mathematics, Walter Sisulu University \\ hcoetzee@wsu.ac.za \\ Riette Maritz \\ Dept. of Mathematics, University of South Africa \\ maritr@unisa.ac.za
}

\begin{abstract}
The study seeks to investigate the status of supplementary tuition in the teaching and learning of mathematics and mathematical literacy. The study followed a descriptive survey design involving the use of learner and teacher questionnaires. A convenient sample of mathematics and mathematical literacy teachers together with a stratified sample of their Grade 11 learners were drawn from a purposive sample of highperforming high schools in the East London district of the Eastern Cape, South Africa. The results show that supplementary tuition is popular, especially among girls, and it is in three forms (i.e. private tuition, vacation school and problem-solving classes): Problemsolving classes dominated by working on past/model examination papers is the most preferred; in some instances supplementary tuition is offered for a fee; it is not only confined to poor performing learners; and participation in supplementary tuition is influenced by a variety of factors.
\end{abstract}

A number of Asian countries have showed remarkable mathematics performance in recent international comparison studies, e.g., the Third International Mathematics and Science Study-Repeat (TIMSS-R) (Howie, 1999), Programme for International Student Assessment (PISA) (OECD, 2001) and the Southern African Consortium for Monitoring Educational Quality Project II (SACMEQ) (Moloi, 2000). The good performance by the Japanese learners, for example, has impressed countries such as the United Kingdom to such an extent that they made some efforts to emulate the Japanese school system. Howie (1999) reports that the Japanese learners tend to perform well in the international comparison studies mainly because of the extensive use of supplementary tuition, which is defined in the current study as extra tuition given to learners outside the normal school time which can be in the form of private tuition, vacation school and problem-solving classes. During the day learners are exposed to the mathematics content through the teacher-dominated lessons and the afternoon lessons focus on conceptual understanding through problem solving-oriented lessons. In South Korea, in addition to 10 hours of normal teaching, a typical day starts with an hour of morning studies and end up with 4 to 6 hours of evening classes (Lee, 2002). The use of supplementary tuition has also been recorded in countries such as Hong Kong, Sri Lanka, Taiwan, India, Cambodia and Malaysia (Bray, 2003). The study by Baker, Akiba, LeTendre and Wiseman (2001) showed that more than 50\% of Grade 7 learners in Japan, Hong Kong, Latvia, Russia, Czech Republic, Slovakia and Slovenia receive supplementary tuition. Bray and Kwok (2003) indicate that more than 70\% of Grade 7 learners in Japan, Hong Kong, Latvia, Russia, Czech Republic, Slovakia and Slovenia have received supplementary tuition at some point in their schooling 
career. Due to the importance of mathematics in various careers such as engineering, economics, architecture, computer science, commerce and so on, a higher premium has been placed on it. It is for this reason that in Germany, for example, where the prevalence of supplementary tuition is relatively low, extra tuition in mathematics seems to be the most sought after (Mischo \& Haag, 2002, p. 264).

To this end, the use of supplementary tuition has not only improved the learner performance in the international comparison tests, but it also benefited learners in their school work. Jacob and Lefgren (2002), in the United States of America, found evidence of substantial positive effects of supplementary tuition (in the form of extra lessons offered during summer holidays) on mathematics which remained considerable even two years after completing the programme. Studies conducted by Posner and Vandell (1999) and MacBeath, Kirwan and Myers (2001) found structured after-school programmes in Great Britain to be particularly beneficial to learners from disadvantaged backgrounds. In Israel, a supplementary high school intervention programme targeting $10^{\text {th }}$ to $12^{\text {th }}$ graders effected an increase in the mean matriculation rate by $3,3 \%$ and improved the learners' probability of earning a matriculation certificate by $12 \%$, which amounted to the overall improvement of 22\% (Lavy \& Schlosser, 2004). Supplementary tuition has also been shown to have a positive influence on attitudes and self-concept, even at low participating levels (Camp, 1990). Furthermore, it is noticeable that countries where supplementary tuition is prevalent have shown considerable technological advancement accompanied by economic growth. Typically, countries such as Japan, Singapore and South Korea have not only shown their learners performing well in international comparison tests, but are also rapidly progressing technologically.

There have been some negatives associated with supplementary tuition in some quarters. Bray (1999, p. 9) mentions that supplementary tuition, due to the significant impact it has had on learning (Camp, 1990; Jacob \& Lefgren, 2002; Lavy \& Schlosser, 2004; Macbeath et al., 2001; Posner \& Vandell, 1999), has generally developed into a huge business enterprise. Parents are prepared to pay considerable amounts of money on supplementary tuition with a view to getting their children to have a competitive edge (Bray, 1999, p. 39). In fact it has been established that there is a strong relationship between learners' opportunity to participate in supplementary tuition and their socio-economic background (Ireson, 2004; Paviot, Heinsohn \& Korkman, 2007). According to Smyth (2008) this has led to participation in supplementary tuition being disproportionally concentrated among learners from middle-class families. It also stands to reason that learned parents are likely to get better paying jobs, thus they are in a better financial position to have money to pay for supplementary tuition. Bray $(1999$, p. 65) notes that South Korean parents spent about $25 \%$ of their income to ensure that their children get good education involving supplementary tuition. Petterson (1993) reports that in 1988 Japanese families paid an average of US\$240 per month per child for supplementary tuition. In certain instances the benefits of being a supplementary tuition provider have caused teachers to conduct themselves in an undesirable manner. For example, Foondun (2002) has found that in countries such as Russia, Egypt and Nigeria teachers somehow manipulate the mainstream system to their advantage by slacking at their teaching and this creates more charged tutoring opportunities for themselves. Similar practices have also been found in Cambodia (Lee, 2002). Supplementary tuition has also contributed to the exodus of teachers with rare skills from the mainstream education. Upon realising the financial benefits of being a supplementary tuition provider, teachers in Costa Rica and Lithuania resigned their positions in schools and opted to be a provider of supplementary tuition (Bray, 1999).

\section{Supplementary tuition in South Africa}

There has been a deluge of supplementary tuition in mathematics in South Africa. One possible reason for the proliferation of supplementary tuition is that learners may be receiving extra tuition because of the shortage of qualified mathematics teachers. The issue of limited qualified mathematics teachers was alluded to by the Minister of Education in her address at the Agrey Klaaste Mathematics, Science and Technology Teacher of the year Award. She indicated that of the 27000 mathematics teachers in service in 2005, 18000 (66,7\%) had proper qualifications (Pandor, 2005). A similar observation has been made by Blaine in Business Day newspaper of November 24, 2007, where she asserts that too few mathematics teachers in South Africa know enough about mathematics or have been trained properly. In this regard the current study seeks to establish why learners take supplementary tuition. 
Another possible reason for the high demand of supplementary tuition in South Africa may be that the syllabi are too full. Moloi (2000) noted that it takes time to learn mathematical skills and especially how to transfer these skills from familiar to unfamiliar situations. Moloi, therefore, enquired whether it would benefit anyone if time spent on mathematics during school time, is increased.

The need to obtain examination results that meet admission requirements in most tertiary studies seems to have prompted the use of supplementary tuition. In general, the majority of learners taking supplementary tuition are those who are doing well or want to do well, particularly in their further studies (Reddy, Berkowitz, \& Mji, 2005). The current study intends to verify this. As in other countries, supplementary tuition in South Africa is normally offered at a fee. Bray (1999, p. 39) notes that supplementary tuition in some societies is offered by university students to raise money for their studies, retired teachers to supplement income from their pension savings and the unemployed graduates. Reddy et al. point out that the Department of Science and Technology (DST) commissioned the Human Sciences Research Council (HSRC) in 2003 to conduct a study on supplementary tuition. Among others, the study sought to assess the extent, nature and cost of supplementary tuition in mathematics, physical science and computer studies for secondary school learners. The study reported that supplementary tuition was mostly conducted after school hours and focused a great deal on the curriculum and past examination papers. In terms of the number of learners participating in supplementary tuition, there were no definitive statistics available. Reddy et al. (2003, p. 9) alluded to the difficulty of determining the exact numbers of learners involved in supplementary tuition mainly because of the different modes of teaching used to offer supplementary tuition. It is for this reason the present study is being pursued to determine the dominant mode of teaching used in supplementary tuition.

In sum, the study will attempt to investigate the status of supplementary tuition in the teaching and learning of mathematics (mathematical literacy is also implied) by determining why learners do take or not take supplementary tuition, the nature of supplementary tuition offered and which learners take supplementary tuition.

\section{Methodology}

\section{Research design}

Given the nature of the study, a descriptive survey design was used to attempt to address the aims of the study.

\section{Sample}

A purposive sample of nine former model $\mathrm{C}$ suburban schools was identified on the basis of their performance in the East London School District of the Eastern Cape Province in South Africa. These schools had obtained an average Grade 12 mathematics pass rate of above $80 \%$ in previous years. From these schools, a stratified sample of 430 Grade 11 learners was proportionally selected. This was the first Grade 11 class to study the new curriculum, namely the National Curriculum Statement (NCS). In terms of NCS's policy, learners who do not study mathematics are compelled to register for mathematical literacy. When sampling, it was ensured that there was a comparable split of the number of mathematics and mathematical literacy learners (the idea to include mathematical literacy mainly emanated from the fact that its introduction in the school curriculum compounded the perennial problem of shortage of properly qualified mathematics teachers. The education authorities then considered training teachers with limited mathematics background to teach mathematical literacy as a way to deal with the problem. Furthermore, mathematical literacy was made compulsory to learners as an alternative to mathematics. Given the learning difficulties most learners generally have with a figure-oriented subject such as mathematical literacy, one would obviously expect such learners to seek extra help to overcome the cognitive challenges posed by the subject).

For teachers, a convenience sample of those teaching mathematics and mathematical literacy in Grades 10-12 teachers took part in the study. The teachers were derived from these classes since it is a common practice in most schools to have a Grade 12 teacher also responsible for either Grade 11 or 10 as well. Furthermore, teachers responsible for mathematics, normally also teach mathematical literacy. 


\section{Instruments}

Two questionnaires (for teachers and learners, respectively) were adapted from a study Improving the Teaching of Science and Technology in the New South Africa (Rochford, Sokopo, \& Kleinsmith, 1997). The modifications on the questionnaires were made to satisfy the aims of the current research and according to the experience and outcomes of the pilot study which was conducted a year earlier in a school with features similar to those of the main study.

The learner questionnaire was in two parts where the first had three sections that elicited the biographical data of learners, details on supplementary tuition exposed to and reasons for not taking supplementary tuition, respectively. The second part of the questionnaire sought to determine reasons why learners were not satisfied with their performance. The teacher questionnaire also had two parts where the first consisted of two sections that derived the biographical data of the teachers and teachers' views about the mathematics syllabus. Part two of the questionnaire drew the teachers' opinion on possible reasons for unsatisfactory performance in mathematics.

The appropriateness of the questionnaires for the purpose of the study was determined by giving them to other mathematics teachers in the district to administer to their learners and also comment on. The reliability was determined by comparing the results yielded in both the pilot and main study to establish any consistency.

\section{Data collection}

Teachers completed their questionnaire individually while the learners completed the questionnaires at their respective schools under the supervision of their mathematics teachers. All the completed questionnaires were then packed for collection by the researcher.

\section{Data Analysis}

The data were analysed according to the assumptions made and linked to the aim(s) and objectives of the study. Three assumptions were made for "why learners take or do not take supplementary tuition?" Firstly, it was assumed that most of the learners who take supplementary tuition are dissatisfied with their performance in mathematics. The presumed dissatisfaction could have many causes, e.g. ineffective or sub-standard teaching, big classes, learners who are over-committed in other areas, long (select a better word) syllabi, lack of resources, etc. These avenues were explored. Secondly, it was also assumed that learners have high expectations of their performance in mathematics, possibly because of the enrichment strategy. Lastly, it was assumed that some learners and/or teachers may view the formal allocation of school time for mathematics as inadequate.

For the question "what is the nature of the supplementary tuition offered?" the investigation focused on the form of supplementary tuition most preferred and why it was popular, as well as the amount of time spent on it. The focus of problem solving classes was also sought. The last question, namely, "who takes supplementary tuition?" mainly determined the gender and ratio of mathematics learners to those who take mathematical literacy. For the latter, the distinction between the mathematics and mathematical literacy learners was based on the fact that learners opting for mathematics in Grades 10-12 are normally those who have shown prowess in the subject since mathematics is optional after Grade 9 in South Africa.

\section{Findings}

The data show that of the learners who took part in the study, about $53 \%$ studied mathematics and the rest had enrolled for mathematical literacy. In terms of gender, mathematics was studied by more females than males. That is, $44 \%$ were male and the rest were females. For mathematical literacy, there was an equal split.

The study also determined the satisfaction levels of learners with their performance. The data revealed that $48 \%$ of learners were not satisfied with their performance and about $42 \%$ of them felt that teachers were not giving them individual attention. Figure 1 provides a graphical summary of the satisfaction level of the learners. 


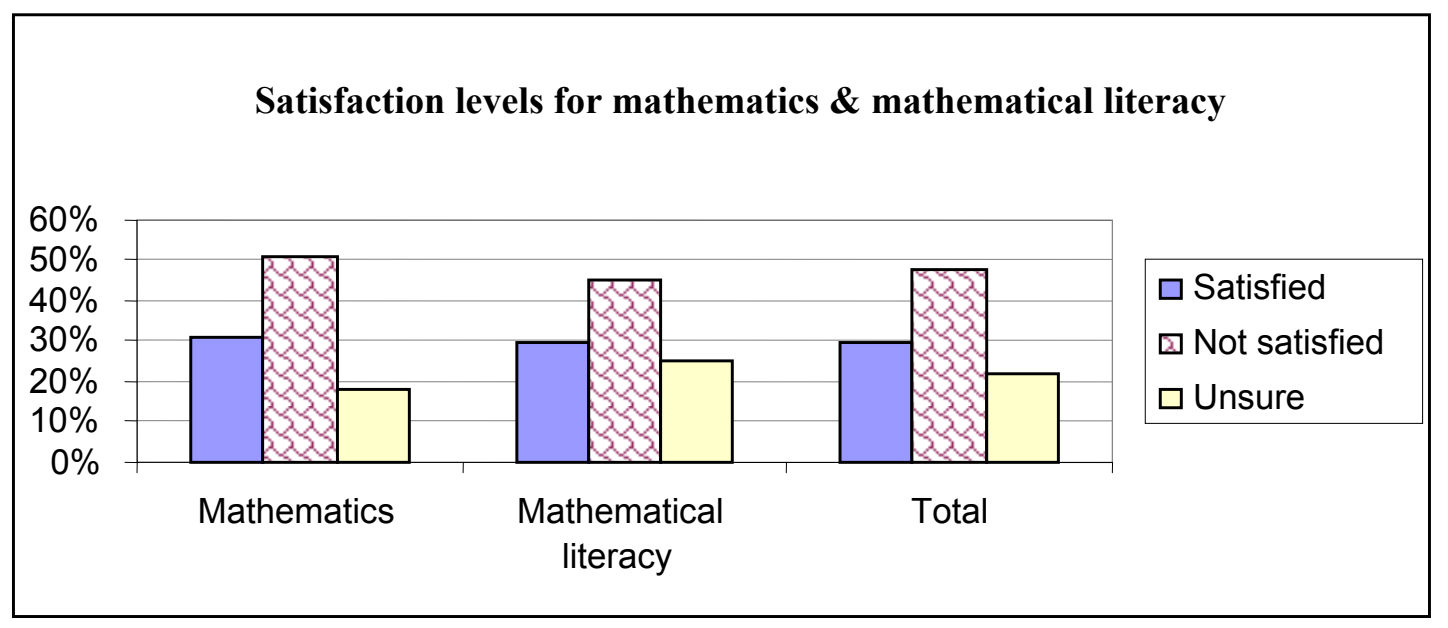

Figure 1: Satisfaction levels

Figure 1 shows that more mathematics learners than mathematical literacy learners are not satisfied with their performance. About the same number of learners in the two subjects is satisfied with their performance and there were more mathematical literacy learners who were unsure about their views than those of mathematics.

Regarding the perceptions of learners about the importance of mathematics or mathematical literacy in their future careers, the data indicate that $90 \%$ regard a good pass in mathematics/mathematics literacy as important for their future careers. Figure 2 presents an analysis of data on how the learners of the respective subjects responded.

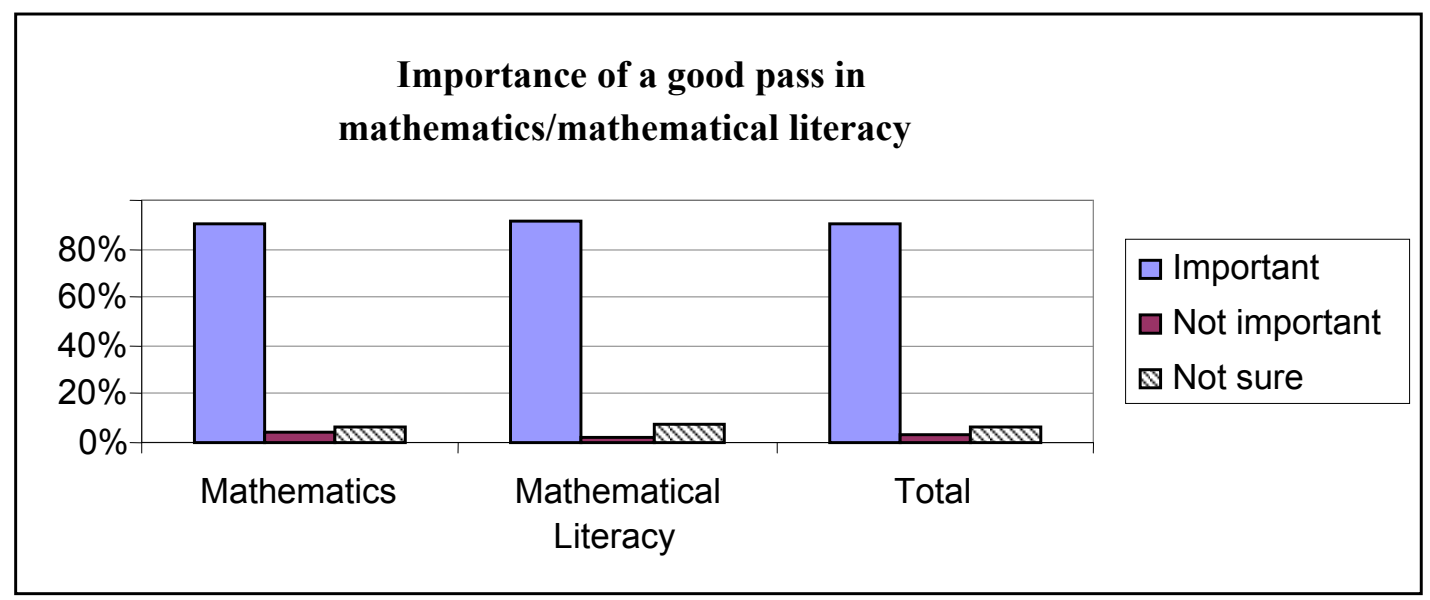

Figure 2: The importance of a good mathematics/mathematical Literacy pass

Figure 2 shows that an overwhelming number of learners considers a good pass in mathematics or mathematical literacy important for their future careers. Given the importance learners attach to their future careers, it was necessary to establish whether they were content with the time allocated to mathematics/mathematical literacy in the school time table. Figure 3 presents the results.

In total, a substantial number of mathematics/mathematical literacy learners (42\%) were not happy with the amount of school time allocated as compared to $20 \%$ who seemed happy with the time spent on mathematics. Between mathematics and mathematical literacy, about $49 \%$ of mathematics learners wanted more school time for the subject as compared to slightly above $30 \%$ of mathematical literacy learners. According to the policy document of the National Curriculum Statement (2005), mathematics and mathematical literacy were each allocated 5 hours per week with 33 to 35 school weeks in a school year. 


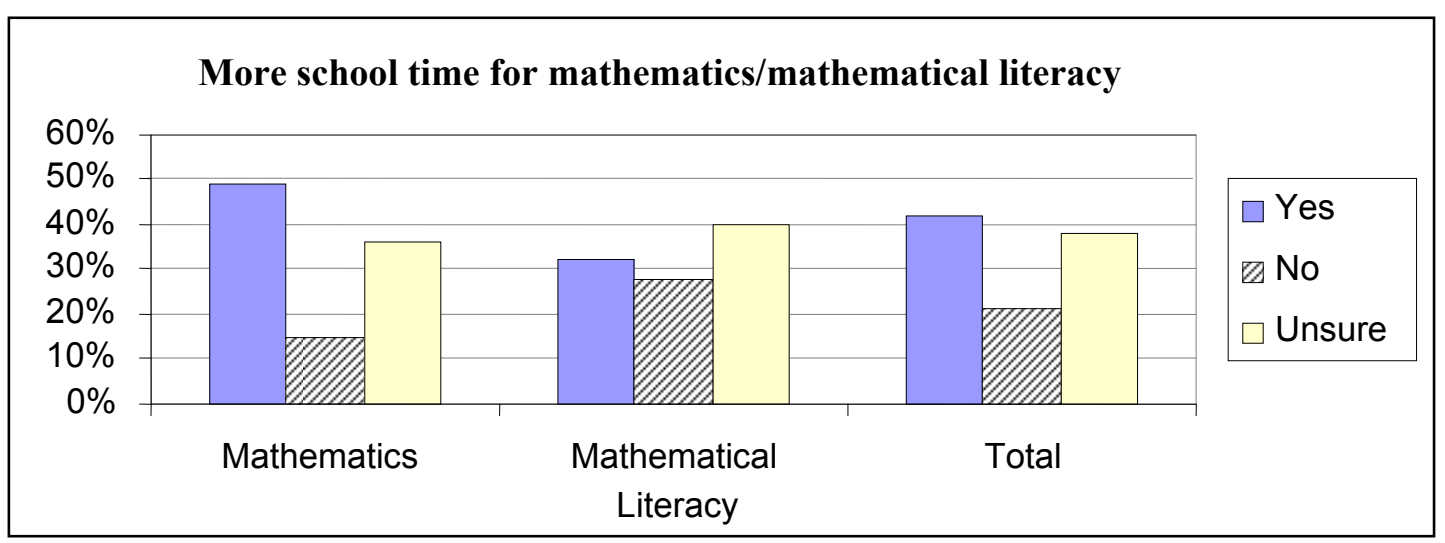

Figure 3: Views of learners on school time for mathematics/mathematical literacy

It emerged that teachers struggle with the volume of work in the new mathematics syllabus in Grades 10 and 11 (the NCS syllabus had not been introduced in Grade 12 at the time of study). About $92 \%$ of those teaching Grade 10 mathematics mentioned that they struggle to complete the syllabus while $83 \%$ indicated that they were having problems with the Grade 11 syllabus. Fewer Grade 12 teachers (29\%) experienced problems with the old mathematics syllabus. Problems were minimal with the completion of the mathematical literacy syllabus. Only $6 \%$ of the Grade 10 and 11 teachers stated that they experienced moderate problems completing the syllabus and none has serious problems. A substantial portion of teachers $(43 \%)$ felt compelled to work fast despite learners finding it difficult to cope. About $47 \%$ of teachers used school time allocated for other activities, e.g. assembly time, library and music periods, and so on to catch up with the mathematics syllabus. A majority of teachers $(91 \%)$ gave learners extra help after school hours where $40 \%$ of them mentioned that it was on regular basis and the rest said extra help was only given when needed. There were teachers (about 24\%) who said they charged to give extra help to learners.

The general view among learners (about 47\%) was the new curriculum was much more demanding and as such the syllabus might not be completed. Learners (about 7\%) also complained that their teacher was often away on other school commitments. About $11 \%$ of learners thought that their teacher did not explain the contents of work clearly and there was no individual attention given by the teacher. It is for these reasons that learners felt that teachers should devise means to catch up by arranging for extra lessons. There were mathematics learners (about 49\%) who wanted more school time devoted to the subject. Teachers, on the other hand, indicated that they were frustrated by the misconceptions learners carried from the lower classes and also expressed some concern about the learners' lack of commitment to their school work in mathematics. What also emerged from the data is that $91 \%$ of the teachers are adequately qualified to teach mathematics in Grades 10-12 because they had post matriculation mathematics and about $18 \%$ of these teachers had a post-graduate qualification in mathematics. The data further show that $44 \%$ of the teachers had been teaching for longer than 20 years and only $21 \%$ had fewer than 9 years teaching experience.

With regards to time spent on supplementary tuition by learners, the data show an average 1,67 hours per week. The mean number of hours spent on supplementary tuition from the beginning of the year up to mid-September, when the survey was done, was 18,23 hours.

Supplementary tuition offered in the participating schools is generally in three forms which are private tuition, vacation school and problem-solving classes. It turns out that problem solving classes, which were mainly dominated by the revision of past/model examination papers, was most preferred (about $83 \%$ ) followed closely by private tuition at $81 \%$ and lastly vacation school at $38 \%$. Given that this was the first Grade 11 group to be taught the new syllabus, the education authorities supplied schools with model examination papers so that teachers could adequately prepare learners for the end-of-year examination. The idea of vacation school was not popular because learners felt that they needed a break during the holidays. In fact, few vacation schools were offered in the area and about $38 \%$ of learners were not sure whether vacation school can help them improve their performance. In general, the proportion of mathematics learners who wanted supplementary tuition was significantly $(t=5,27, d f=288, p<0,0005)$ 
more than that of mathematics literacy. Nevertheless, regardless of the popularity of supplementary tuition there was a range of reasons given by learners who did not take supplementary private tuition. The common ones were: cannot afford supplementary tuition; too much homework in other subjects; being too busy; transport problems; and having an excellent and experienced teacher at school. The data also showed that supplementary tuition was much more popular amongst mathematics learners compared to mathematical literacy learners.

\section{Discussion}

The current study sought to investigate the status of supplementary tuition in the teaching and learning of mathematics/mathematical literacy. Learners in the current study were taught by properly qualified and experienced teachers and yet they still felt it was important to participate in supplementary tuition. Most probably, it is the reinforcement value associated with supplementary tuition that influenced learners to consider it positively. In this regard, it is asserted that the need for supplementary tuition by learners is not dependent on the teachers' qualification and their years of teaching. The learners and teachers came from high performing schools that obtained an average of $80 \%$ plus in the matriculation results over the years. Notably, the schools are located in a suburban area and are former model $\mathrm{C}$ schools. From a historical point of view, these schools were never disadvantaged in terms of resources and they generally drew learners from families that were not financially deprived. This is consonant with the findings by Reddy et al. (2005, p. 2) that supplementary tuition generally targets high performing learners in urban metropolitan schools who can afford it. The findings from the current study, therefore, dispel the perception that generally associates supplementary tuition with low performing learners (Ireson, 2004; Paviot et al., 2007; Smyth, 2008).

What is also apparent from the current study is that there seems to be a range of factors that encourage learners to participate in supplementary tuition. These are:

0 the urge to do well in mathematics/mathematical literacy,

$O$ the significant role learners reckon mathematics/mathematical literacy play in their future careers,

O time devoted to mathematics/mathematical literacy on a school time table is considered inadequate,

0 learners not being able to grasp content because teachers rush through it as a result of limited time available,

- some teachers offer supplementary tuition to supplement their income,

- seemingly some teachers provide supplementary tuition to help learners catch up, and

$\circ$ to provide extra help particularly to learners whom they consider having learning deficiencies.

From this range of factors, there are those that are consistent with the view by Baker et al. (2001, p. 9) that remedial strategy is the dominant reason for taking supplementary tuition and also the importance that learners attach to mathematics to gain access to certain careers. On the other hand, none of the factors is consonant with a finding by Ireson (2004) that social desirability of tutoring tends to urge learners to participate in supplementary tuition and also with an argument by Smyth (2008) that participation in supplementary tuition must be seen in the context of the competitive examination system in operation. Furthermore, considering that in South Africa mathematical literacy is compulsory even to learners with a deficient capacity and phobia for figures, one would expect far more mathematical literacy learners to participate in supplementary tuition than mathematics learners. The current study presents a different picture altogether. That is, preference for supplementary tuition is strong among mathematics learners. It may be due to the cognitive challenges mathematics poses, inadequate time available on school time table for mathematics, and an urge by learners to perform well, so that they can pursue their dream careers. There may still exist then/also quite some apathy, confusion and lack of quality/commitment among both learners and teachers in this regard, as part of the more perennial problem of an ailing education system and this will be much bigger in non-former Model $\mathrm{C}$ schools.

It would also seem that participation in supplementary tuition is gendered. More girls than boys prefer supplementary tuition. Bray (1999) came up with similar findings in the study that was carried out in Egypt, Malaysia, Malta, Taiwan and Japan. A possible explanation for this is derived from Fennema and Hart (1994) and Volman and van Eck (2001), who report that girls are generally prejudiced in mathematics classes. On one hand, largely in classes taught by males, girls tend to be snubbed or ignored 
in the lesson's activities. Volman and van Eck indicate that such a practice tend to instil among girls a sense that they lack capacity for mathematics or teachers simply do not have confidence in the girls' ability to cope with mathematics. Gender-stereotypical behaviour against girls, on the other hand, tends to be displayed by their male counterparts. For example, Mogari (2002) found such behaviour manifesting in the cooperative learning groups during mathematics lessons. Girls were denied full participation in the lesson's activities by boys and subsequently boys outperformed girls. The overwhelming recognition by learners of the importance of a good pass in mathematics may well have prompted girls to seek supplementary tuition to circumvent the teaching and learning difficulties they experience in their classes.

Of the three forms of supplementary tuition that are found in the current study, revising past examination papers is the most popular and is closely followed by private tuition, with vacation tuition being the least popular. It stands to reason that revision of examination papers is popular because of its easy availability and the low cost involved. In fact, past examination papers with worked solutions are on sale at a reasonable price in most stationery stores in South Africa. Furthermore, the Department of Education has also made available past/model examination papers through the internet and newspapers, and this mode of delivery is cost effective. There are schools that are supplied daily with free editions of newspapers containing supplements of various learning materials including past/model examination papers. Those schools that are not supplied with free newspapers buy them. Probably the relative ease with which past/model examination papers is made available to learners has somehow influenced the learners' preference for this form of supplementary tuition.

What is also notable is a fairly considerable proportion of learners (about 38\%) being negative about vacation school. Some learners feel they need a break from their busy learning schedule while others are apprehensive about its potential to help them better their achievements. With regards to the former, learners feel they would rather utilise a form of supplementary tuition that does not encroach on their private time. A possible explanation, for the latter, is that in most cases the lesson structure of vacation school is similar to the ordinary, normal school lessons. Perhaps learners think they might still encounter learning difficulties they usually experience during the normal school lessons. For private tuition, it is probably highly preferred because it provides an opportunity for a learner to have special individual attention that may tend to be very helpful. This observation is consistent with the view by Ireson (2004) that learners value the one-on-one attention that they get in supplementary tuition and see it as an opportunity to enhance understanding. But it is speculated that the financial expenses associated with private tuition, made it not to be the most preferred form of supplementary tuition. Another possible reason for the popularity of working on model/past examination papers is its flexible nature, where learners can work individually or in a group whenever it is convenient for them.

However, there are factors that tend to impede learners from participating in supplementary tuition regardless of their willingness to do so. The factors, among others, are social, economic and educational in nature. The fact that some learners could not participate in supplementary tuition due to financial problems corroborates allusions by Ireson (2004) and Paviot et al. (2007) that there is a strong relationship between learners' ability to participate in supplementary tuition and their socio-economic background and by Bray (1999) that supplementary tuition seems to create and perpetuate social inequalities. For the latter, it should be noted that learners with financial difficulties cannot benefit from supplementary tuition regardless of its proven effectiveness (Camp, 1990; Jacob \& Lefgren, 2002; Lavy \& Schlosser, 2004; Macbeath et al., 2001; Posner \& Vandell, 1999). Learners who are unable to participate in supplementary tuition have to rely solely on the normal school tuition which, as evident in the current study, seems never to be devoid of problems. It is suggested that further investigations identify all these problems and possibly suggest ways and means to find sustainable solutions to them.

What has also emerged serendipitously from the study are some of the challenges posed by the new curriculum. Firstly, given its much more context and activity based nature, the new curriculum requires different timetabling arrangements. It would appear the time set aside for mathematics lessons has to be increased so that the entire prescribed syllabus could be covered. Secondly, teachers need to adapt their teaching knowledge and skills to the instructional requirements of the new curriculum. This will enable them to plan the lessons accordingly and be able to appropriately time the different steps of the lessons. Through these, each offered lesson will properly fit the allocated slot on the time table, thus enabling the 
teachers to teach effectively and complete the syllabus. Lastly, teachers need to be given the necessary training so that they could properly implement the new curriculum and achieve its desired goals.

In conclusion, the study has revealed some rather significant findings about supplementary tuition. That is, it is not only confined to poor performing learners; parents are anxious about ensuring their children acquire plausible education; learners' participation in supplementary tuition is driven by an urge to acquire good results and enhance opportunities to study what may be referred to as financially rewarding science-related careers (e.g. engineering; actuarial science; medicine and so on); some teachers participate in supplementary tuition for financial benefits; girls use supplementary tuition to make up for the teaching and learning challenges they experience in their classes; and there are still problems associated with NCS implementation in the schools.

\section{References}

Baker, D. P., Akiba, M., LeTendre, G. K., \& Wiseman, A. W. (2001). Worldwide shadow education: Outsideschool learning, institutional quality of schooling, and cross-national mathematics achievement. Educational Evaluation and Policy Analysis, 23(1), 1-17.

Bray, M. (1999). The shadow education system: Private tutoring and its implications for planners. Paris: UNESCO, International Institute for Educational Planning.

Bray, M. (2003). Adverse effects of private supplementary tutoring: Dimensions, implications and government responses. Comparative Education research Centre, The University of Hong Kong.

Bray, M., \& Kwok, P. (2003). Demand for private supplementary tutoring: Conceptual considerations and socio-economic patterns in Hong Kong. Economics of Education Review, 22(6), 611-620.

Camp, W. (1990). Participation in student activities and achievement: A covariance structural analysis. Journal of Educational Research, 83(2), 272-278.

Department of Education. (2005). National curriculum statement Grades 10-12 (General). Learning programme guidelines. Mathematical Literacy. Pretoria: National Department of Education.

Fennema, E., \& Hart, L. E. (1994). Gender and the JRME. Journal for Research in Mathematics Education, 25(6), 648-696.

Foondun, A. R. (2002). The issue of private tuition: An analysis of the practice in Mauritius and selected South-East Asian countries. International Review of Education, 48(6), 485-515.

Howie, S. (1999). Third International Mathematics and Science Study Repeat (TIMSS-R). Executive summary. Cape Town: HSCR Press.

Ireson, J. (2004). Private tutoring: How prevalent and effective is it? London Review of Education. London: Carfax Publishing.

Jacob, B., \& Lefgren, L. (2002). Remedial education and student achievement: A regression-discontinuity analysis. Working Paper 8918. Massachusetts: National Bureau of Economic Research (NBER).

Lavy, V. \& Schlosser, A. (2004). Targeted remedial education for under-performing teenagers: Costs and benefits. Working Paper 10575. Massachusetts: National Bureau of Economic Research (NBER).

Lee, J. (2002). Education policy in the Republic of Korea: Building block or stumbling block? Washington, D.C.: The World Bank.

MacBeath, J., Kirwan, T., \& Myers, K. (2001). The Impact of study support. London: DfEE.

Mischo, C., \& Haag, L. (2002). Expansion and effectiveness of private tutoring. European Journal of Psychology of Education, 17(3), 263-273.

Mogari, D. (2002). An ethnomathematical approach to the teaching and learning of some geometrical concepts. (Unpublished doctoral dissertation). University of the Witwatersrand, Johannesburg.

Moloi, M. Q. (2000). Mathematics achievement in South Africa: A comparison of the official curriculum with pupil performance in the SACMEQ (Southern African Consortium for Monitoring Educational Quality) II Project. Retrieved from www.jet.org.za/.

OECD. (2001). Knowledge and skills for life: First results from the OECD programme for international student assessment (PISA) 2000. Paris: OECD publications.

Pandor, N. (2005). Address by the Minister of Education, (Ms Naledi Pandor, MP) at the Agrey Klaaste mathematics, science and technology Educator of the Year award. Department of Education. Retrieved from http://education.pwv.gov.za.

Paviot, L., Heinsohn, N., \& Korkman, J. (2007). Extra tuition in Southern and Eastern Africa: Coverage, growth, and linkages with pupil achievement. International Journal of Educational Development, 28(2), 149-160. 
Petterson, L. (1993). Japan's 'cram schools'. Educational Leadership, February, 56-58.

Posner, J., \& Vandell, D. L. (1999). Low-income children's after-school care; are there beneficial effects on after-school programs? Developmental Psychology, 35, 868-879.

Reddy, V., Lebani, L., \& Davidson, C. (2003). Schools out ...or is it? Out of school interventions for mathematics, science and computer studies for secondary school learners. Pretoria: Human Science Research Council.

Reddy, V., Berkowitz, R., \& Mji, A. (2005) Supplementary tuition in mathematics and science: An evaluation of the usefulness of different types of supplementary tuition programmes. Pretoria: Human Sciences Research Council.

Rochford, K., Sokopo, Z., \& Kleinsmith, C. (1997) Improving the teaching of science and technology in the new South Africa: Concurrence between the policy preferences of lecturers, teachers and students. Global Journal of Engineering Education, 2(1), 103-118.

Smyth, E. (2008). The more, the better? Intensity of involvement in private tuition and examination performance. Educational Research and Evaluation, 14(5), 465-476.

Volman, M., \& Van Eck, E. (2001). Gender equity and information technology in education: The second decade. Review of Educational Research, 71(4), 613-634. 